\title{
Combined exercise and nutritional rehabilitation in outpatients with incurable cancer: a systematic review
}

\author{
Charlie C. Hall $^{1,2}$ (D) Jane Cook $^{1} \cdot$ Matthew Maddocks $^{3} \cdot$ Richard J. E. Skipworth $^{4} \cdot$ Marie Fallon $^{1,2} \cdot$ Barry J. Laird $^{1,2}$
}

Received: 5 September 2018 / Accepted: 15 March 2019 / Published online: 3 April 2019

(C) The Author(s) 2019

\begin{abstract}
Purpose The optimal components for rehabilitation in patients with incurable cancer are unclear. However, principles of exercise and nutrition-based interventions used in cancer cachexia may be applied usefully to this population of cancer patients. This systematic review examines current evidence for rehabilitation combining exercise and nutritional support in patients with incurable cancer.

Methods MEDLINE, EMBASE and Cochrane databases were searched. Eligible studies included patients with incurable cancer and rehabilitation programmes combining exercise and nutritional interventions. Studies of cancer survivors, curative treatments, reviews, case note reviews, protocols and abstracts were excluded. Grading of Recommendations Assessment, Development and Evaluation (GRADE) criteria were applied to patient-important outcomes.

Results Of the 2424 search results, 67 abstracts were reviewed and 24 full texts examined. Eight studies $(n=685)$ were included comprising two randomised control trials, three prospective, one exploratory and two secondary analyses. All examined multimodal outpatient programmes. GRADE analysis revealed moderate evidence (B) for improvements in depression and physical endurance, low-quality evidence (C) for quality of life and fatigue and very low-quality evidence (D) for overall function and nutritional status.

Conclusion There are limited data for multi-modal rehabilitation programmes combining exercise and nutritional interventions in patients with incurable cancer. However, studies to date report improvements in multiple domains, most notably physical endurance and depression scores. This supports the concept that multi-modal rehabilitation incorporating principles of cachexia management may be appropriate for the wider group of patients with incurable cancer. Further, high-quality studies are needed to define the optimal approach and outcome measures.
\end{abstract}

Keywords Rehabilitation $\cdot$ Palliative medicine $\cdot$ Exercise $\cdot$ Nutrition therapy

\section{Introduction}

Patients with cancer are living longer than ever before; indeed, in many cases, cancer is now considered a chronic disease [1,

Marie Fallon and Barry J Laird are joint senior authors.

Charlie C. Hall

Charlie.hall@ed.ac.uk

1 St Columba's Hospice, 15 Boswall Road, Edinburgh EH5 3RW, UK

2 Institute of Genetics and Molecular Medicine, University of Edinburgh, Edinburgh, UK

3 Cicely Saunders Institute of Palliative Care, Policy and Rehabilitation, Kings College London, London, UK

4 Clinical Surgery, Royal Infirmary, Edinburgh, UK
2]. While this is clearly a positive development, the consequences of patients living longer with cancer are wide and varied. With longer survival comes an increase in morbidity and increased healthcare costs with associated socioeconomic implications [3]. There is a need to take a proactive approach to this evolving situation and to optimise the overall condition of patients living with cancer, including those with incurable disease [4]. Rehabilitation may be one such way of optimising the function and overall quality of life (QoL) of this patient population.

Rehabilitation is a concept widely embraced by Western medicine for the management of acute and chronic illness and has recently been advocated for patients with incurable cancer, including those receiving treatment with palliative intent [5-7]. Although 'rehabilitation' for patients with incurable cancer may seem paradoxical, there is a plausible argument that patients whose overall condition is compromised 
have the most to gain from appropriately tailored intervention [7]. In patients with advanced disease, rehabilitation aims at improving and/or maintaining function where the effects of the illness or its treatment threaten to cause decline, or to ease the transition toward dependency when functional deterioration is inevitable. Promoting patients' own interests and social engagement and optimising functional independence are fundamental [7]. It is acknowledged widely that rehabilitation in patients with incurable cancer should be multi-modal and tailored $[5,7,8]$ yet, there is a lack of evidence as to the most efficacious components of a rehabilitation programme for this patient population [2].

The emerging principles of optimising physical and nutritional function in patients with cancer cachexia would seem appropriate to be applied to a broader rehabilitation concept in all patients with cancer. Cachexia is defined as 'an ongoing loss of skeletal muscle mass (with or without fat mass) that cannot be fully reversed by conventional nutritional support and leads to protein breakdown, and resultant loss of muscle mass and functional decline' [9]. It is common in solid tumours, which account for over $50 \%$ of cancer deaths worldwide and affects over half of all patients with advanced cancer [10]. Cachexia adversely affects function and QoL and is an independent predictor of poorer treatment response, sideeffect profiles and shorter survival [11-13]. The high prevalence of cachexia in patients with incurable cancer alone means that any rehabilitation intervention for this group should consider key components of cachexia.

Cachexia is characterised by involuntary weight loss and a negative energy balance created by reduced oral intake, alterations in body metabolism and inflammation [10]. Dietary interventions alone are not effective in reversing cancerrelated cachexia, [11, 14] due to metabolic alterations including elevated energy expenditure, excess catabolism and inflammation [10], which together prevent muscle anabolism (the 'anabolic blockade') [11]. Exercise stimulates skeletal muscle anabolism, leading to increased muscle mass and strength; however, supra-normal protein intake is required to achieve the same post-prandial anabolic effects in cachectic patients [11]. Introducing exercise without nutritional support in this group of patients may exacerbate the negative energy balance. Work to date has demonstrated that cancer cachexia is best targeted through a pro-active, multi-modal intervention that aims to improve lean mass (muscle), physical function and overall QoL $[11,15]$. This pro-active and multi-modal approach advocated for cancer cachexia has the potential to be adopted usefully as a rehabilitation approach for patients with incurable cancer.

Patients with incurable cancer frequently suffer from symptom clusters (SCs), where two or more interrelated symptoms present together, independent of other SCs: raising the possibly of a common aetiology or mechanism [16]. Examples include the fatigue/anorexia-cachexia and the fatigue/neuro-psychological clusters, which have been clinically and statistically defined. Proinflammatory cytokines may play a role in the aetiology of SCs [17], and thus, the multi-modal rehabilitation approach advocated for cancer cachexia may also play a useful role in the management of SCs.

Exercise is feasible in patients with incurable cancer and has multiple beneficial effects on physical well-being, fatigue and depression, all impacting on overall QoL $[2,18]$. Based on work to date, there is a strong rationale that exercise and nutrition in combination should be key constituents of any rehabilitation programme for patients with cancer; however, the details of any such programme remain to be elucidated [5]. The aim of this systematic review is therefore to examine current evidence for combined exercise and nutritional rehabilitation interventions in patients with incurable cancer.

\section{Materials and methods}

Ethical approval was not required for this systematic review. The following databases were searched electronically: MEDLINE, EMBASE and the Cochrane Library. The time frame was 1990 to current. The keywords and search strategy are outlined in Appendix 1. The literature search was performed between February 26, 2018 and March 5, 2018. A consort diagram (Fig. 1) was performed as per PRISMA guidelines.

\section{Eligibility criteria}

Studies met the following inclusion criteria: patients with incurable cancer (defined as metastatic cancer [histological, cytological or radiological evidence] or locally advanced cancer being treated with palliative intent); rehabilitation programmes including both exercise and nutritional components; all methodologies; studies in humans; and English language.

Studies were excluded if they met any of the following criteria: studies of cancer survivors or carers of cancer patients; unimodal rehabilitation interventions; reviews; protocols; case reports; retrospective case note reviews; conference abstracts; and rehabilitation/prehabilitation for cancers managed with curative intent.

\section{Appraisal process}

Titles were reviewed by $\mathrm{CH}$ then relevant abstracts screened by $\mathrm{CH}$ and $\mathrm{BL}$. Abstracts deemed relevant or requiring clarification were reviewed at full text. Full texts were screened by $\mathrm{CH}$ and $\mathrm{BL}$ and thematic analysis applied by $\mathrm{JC}$ and $\mathrm{CH}$. Estimates of effect extracted from studies included change scores (pre-post measurements), effect sizes and $P$ values. Values were synthesised according to patient-important 
outcomes (see below) as well as outcomes of methodological interest for future study design: feasibility, dropout rates, predictors of completion and cost-effectiveness.

Grading of Recommendations Assessment, Development and Evaluation (GRADE) analyses were undertaken by $\mathrm{CH}$ and JC. Due to the complexity and to improve inter-rater reliability, a checklist was developed [Supplementary material-on request] based on the GRADE handbook and a validated checklist for meta-analyses [19-21]. This was applied to individual studies then to the body of evidence for patientimportant outcomes, which were decided a priori between authors and ranked in order of importance. Where GRADE discrepancies existed, these were discussed among the authors and a consensus reached.

\section{Results}

Figure 1 shows the literature review process. The following numbers of articles were retrieved from each database: 781 (MEDLINE), 1625 (EMBASE) and 18 (Cochrane Database of Systematic Reviews).

A summary of the included studies is detailed in Table 1. Eight studies were eligible enrolling a total of 685 participants. Studies included two randomised control trials (RCTs) [22, 23], three prospective studies [24-26], two secondary analyses of quasi-experimental data [1, 27] and one exploratory study [28]. All interventions were outpatient-based rehabilitation programmes: seven in hospitals and one hospice-based. Three studies examined the 8 to 12 -week McGill Cancer Nutrition Rehabilitation Programme (CNRP) [24-26], and three studies examined the 8-week-Ottawa Palliative Rehabilitation Programme (PRP) [1, 27]. Two studies examined novel rehabilitation programmes in the UK [23] and Switzerland [22]. All programmes were interdisciplinary and were individually tailored. Seven studies included core components combining dietary modification/supplementation and exercise [1, 22, 24-28]. The remaining study included dietary and physiotherapy interventions as an optional (non-core) element dependent on patient goals: it was not possible to ascertain numbers of participants receiving input from both these specialists [23].

Studies and patient-important outcomes and were evaluated using the GRADE approach. Consensus was reached on the quality of evidence for each patient-important outcome, presented in Tables 2 and 3.

\section{Feasibility and adverse events}

Three studies ( $n=300)$ commented on feasibility of the rehabilitation programmes or constituents of their interventions. Patients attended a mean of $67 \%$ of bi-weekly exercise
Fig. 1 Consort diagram to show the literature search process

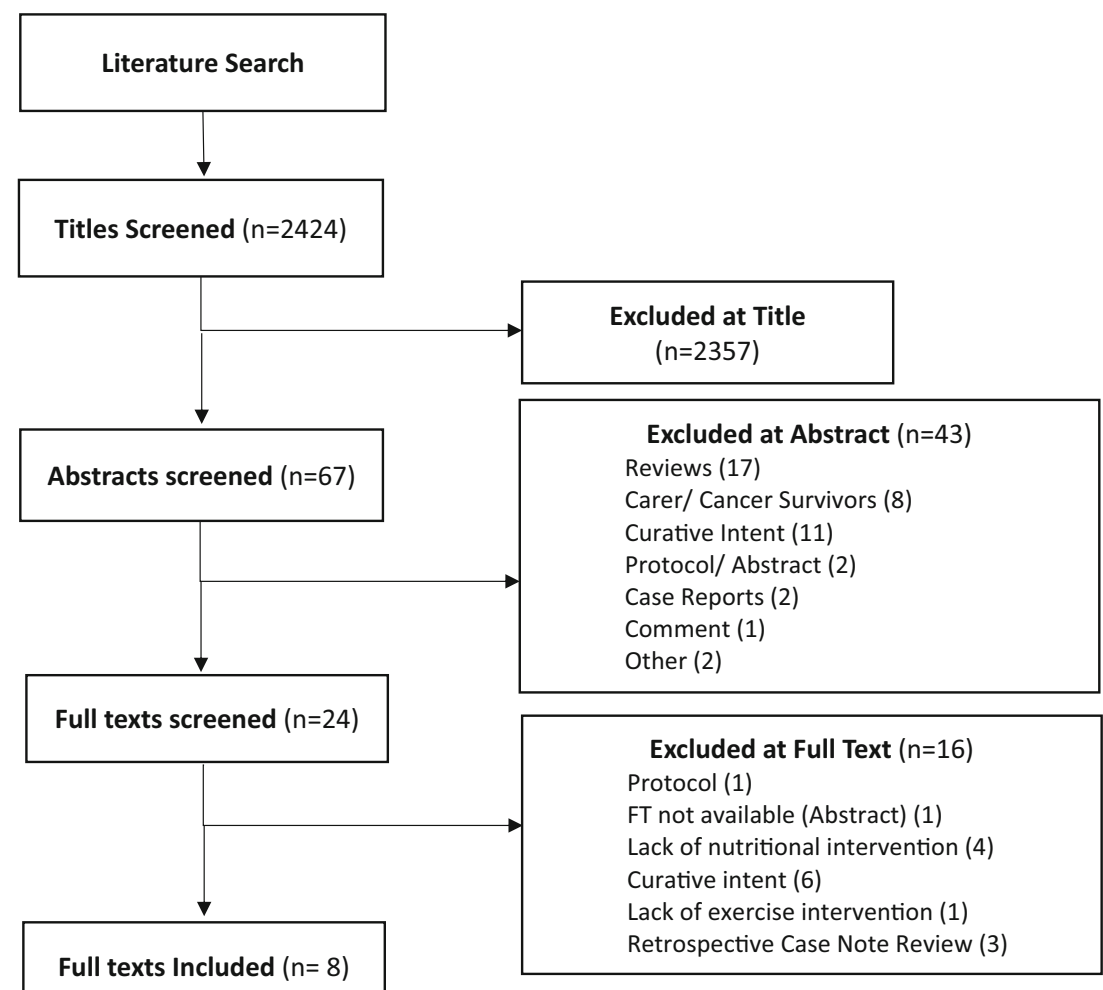




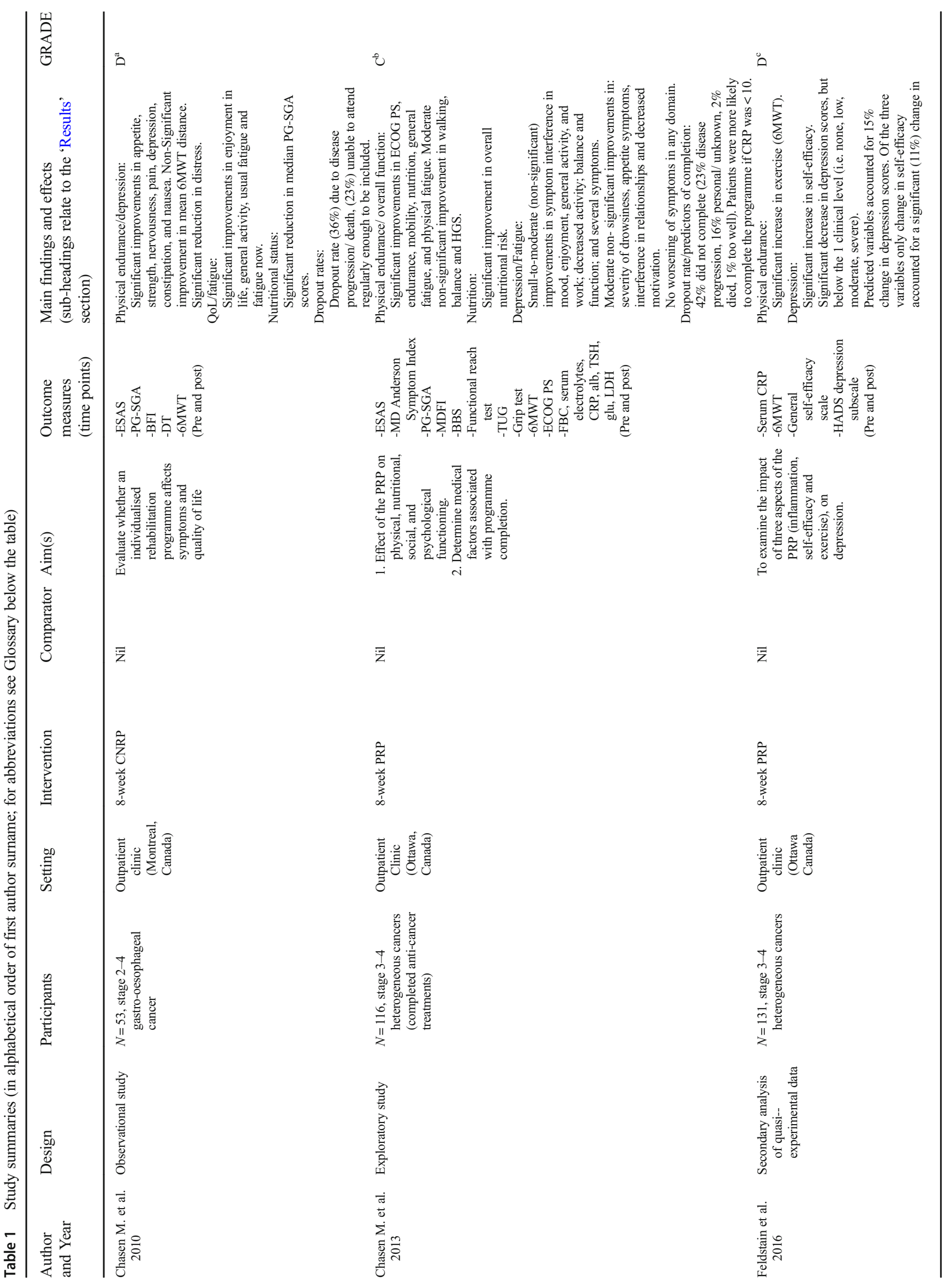




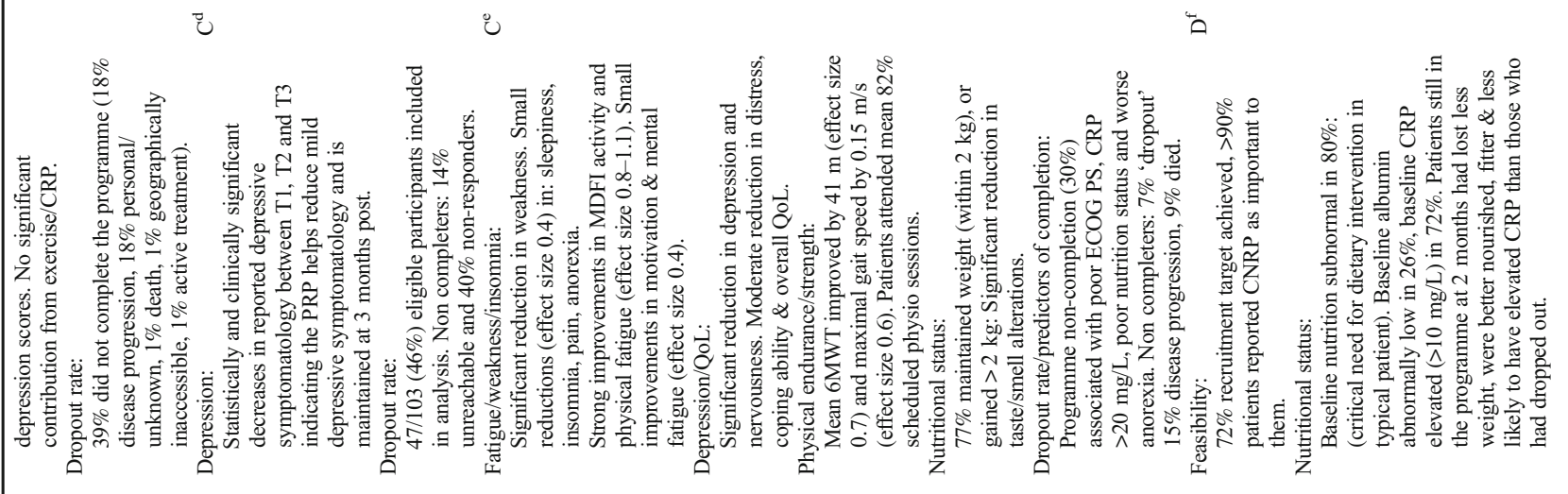

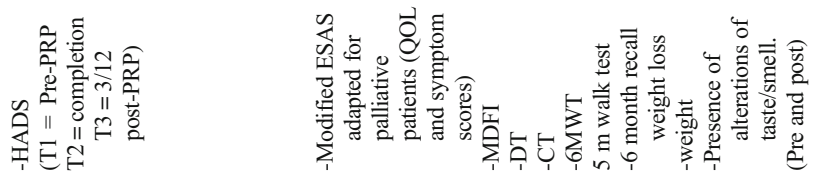
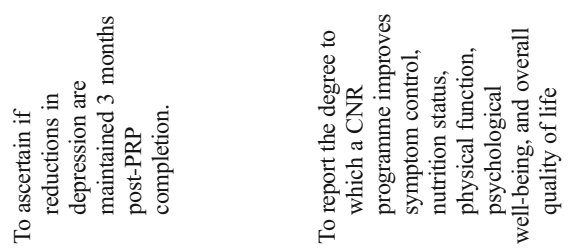

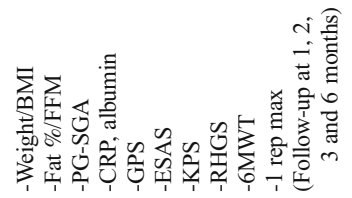

$\bar{z}$

$\bar{z}$

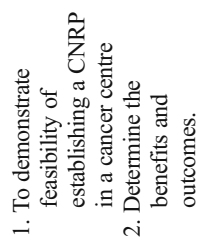

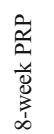

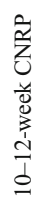

$\bar{z}$

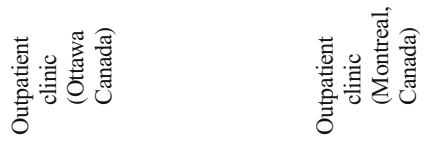

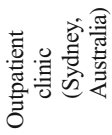
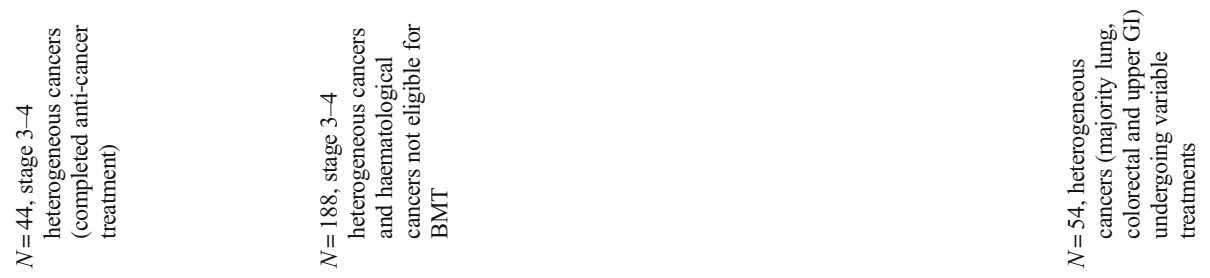

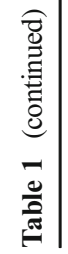
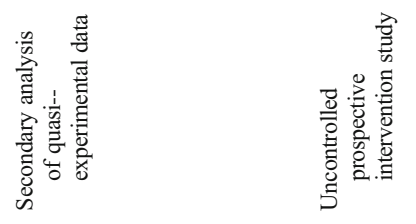

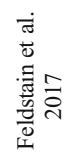

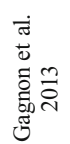

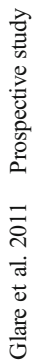




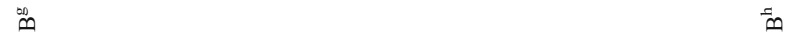

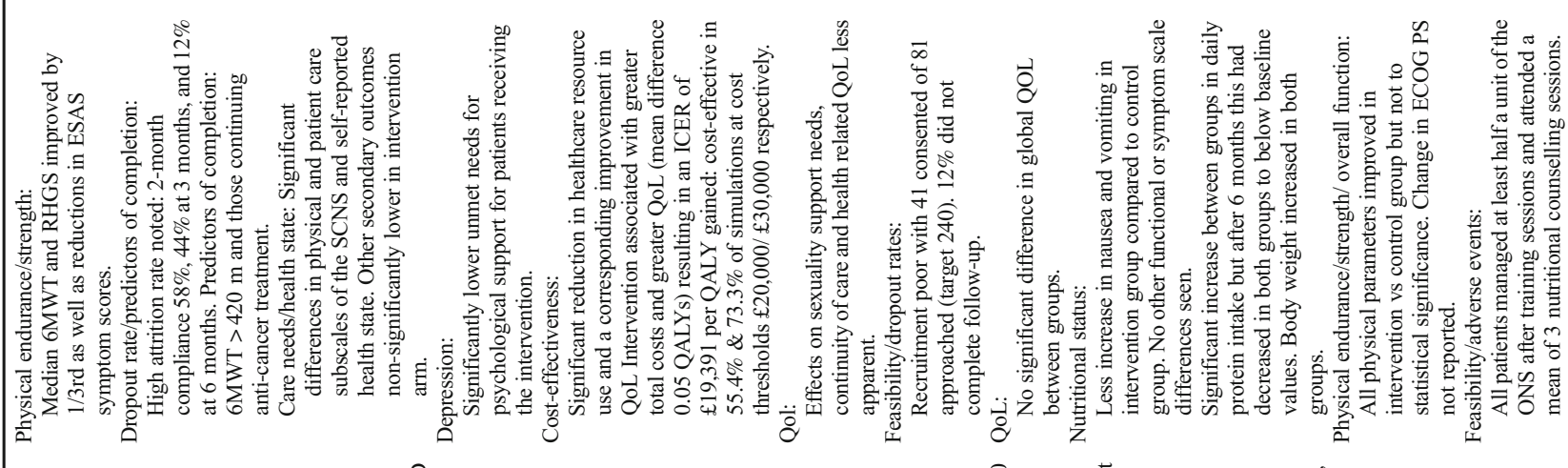

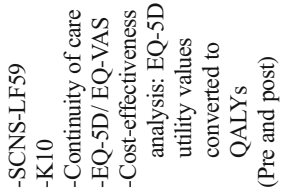

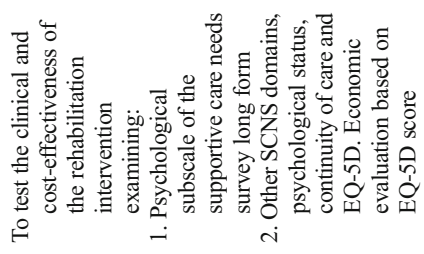

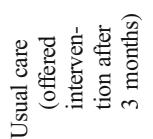

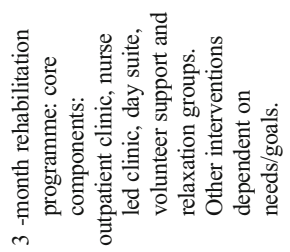

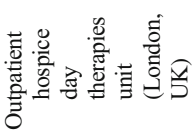

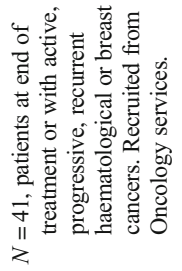

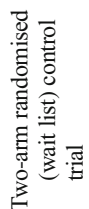

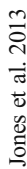

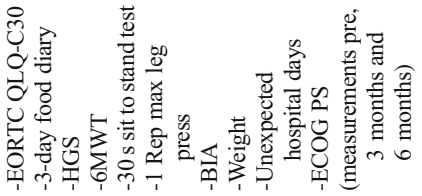

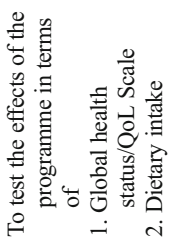

IIIII
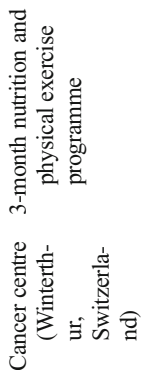

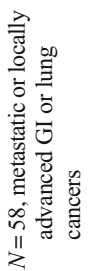

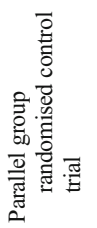

气

곤

竞 


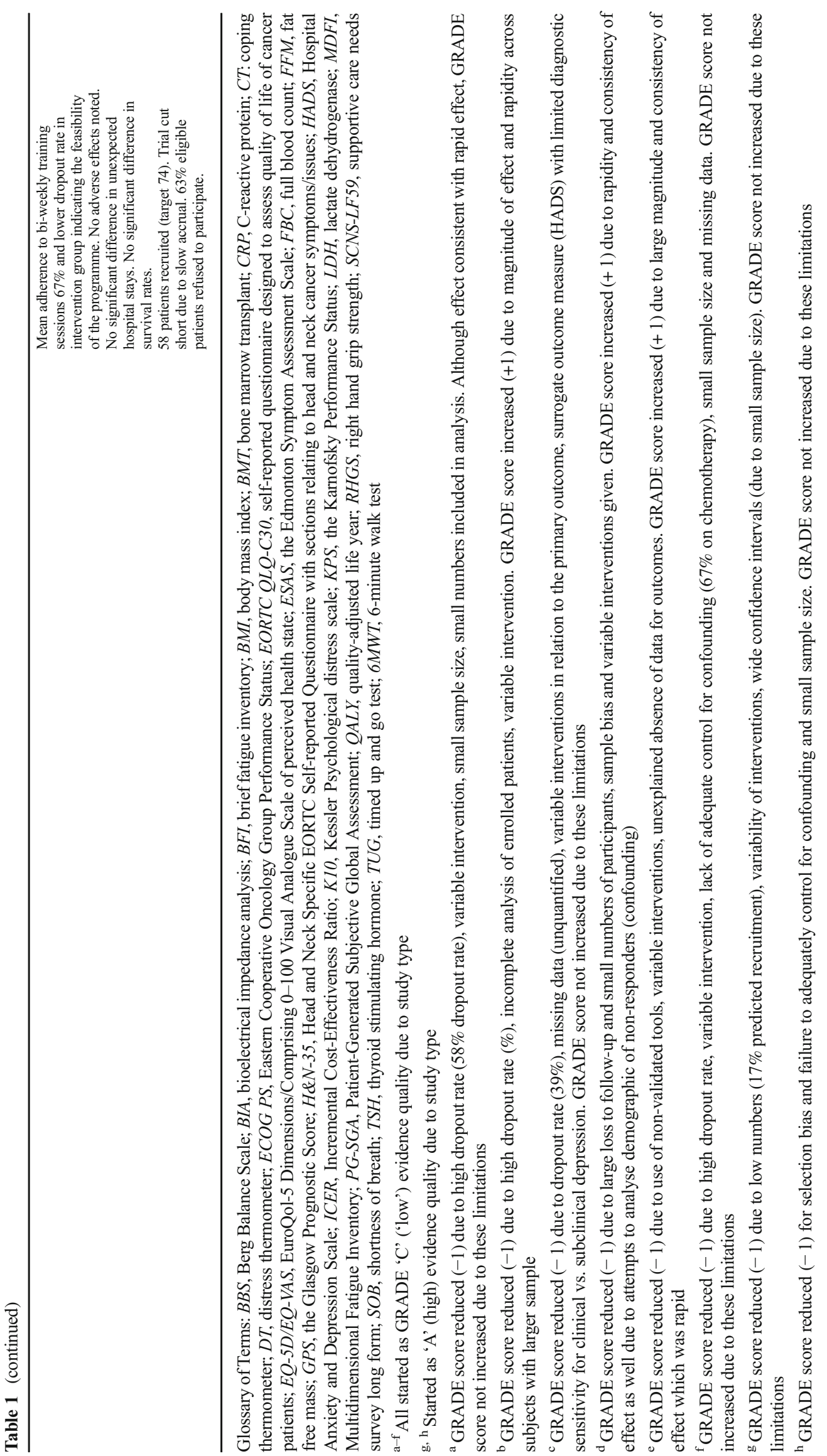


Table 2 Summary of findings: modified due to study types. Patients or population: patients with incurable cancer. Settings: outpatient. Intervention: multi-modal rehabilitation programmes comprising exercise and nutritional elements. Comparison: where available-standard care

\begin{tabular}{|c|c|c|c|c|}
\hline $\begin{array}{l}\text { Patient- important } \\
\text { outcomes }\end{array}$ & Studies & $\begin{array}{l}N=\text { total participants* } \\
\text { (breakdown per } \\
\text { outcome measure) }\end{array}$ & $\begin{array}{l}\text { Quality of the } \\
\text { body of evidence } \\
\text { (GRADE) }\end{array}$ & Comments \\
\hline Quality of life & $3[22,23,26]$ & $\begin{array}{l}N=214 \\
129(\text { ESAS }) \\
41 \text { (EQ-VAS) } \\
44(\text { EORTC C30) }\end{array}$ & Low $(\mathrm{C})$ & $\begin{array}{l}\text { Two moderate quality studies with conflicting results, one } \\
\text { low-quality study showing improvement, studies have } \\
\text { limitations and inconsistencies in outcome variables. }\end{array}$ \\
\hline Overall function & $2[25,28]$ & $\begin{array}{l}N=81 \\
56(\text { ECOG PS) } \\
25(\text { KPS })\end{array}$ & Very low (D) & $\begin{array}{l}\text { Two studies with low and very low-quality examined changes } \\
\text { in functional status scores, one finding significant and one } \\
\text { non-significant improvements. Sparse data with limitations. }\end{array}$ \\
\hline Fatigue & $4[22,24,26,28]$ & $\begin{array}{l}N=203 \\
22(\mathrm{BFI}) \\
137(\mathrm{MDFI}) \\
44 \text { (EORTC QLQ-C30) }\end{array}$ & Low (C) & $\begin{array}{l}\text { Two low, one very low-quality studies with limitations } \\
\text { showing significant improvements in fatigue in spite of } \\
\text { sparse data, and one high-quality (underpowered) study } \\
\text { showing non-significant improvements in intervention } \\
\text { group compared to control }\end{array}$ \\
\hline $\begin{array}{l}\text { Physical } \\
\text { endurance/- } \\
\text { strength }\end{array}$ & $6[22,24-28]$ & $\begin{array}{l}N=342 \\
6 \text { MWT (342) } \\
\text { HGS ( } 64 \text { within two of } \\
\text { the above studies) }\end{array}$ & Moderate (B) & $\begin{array}{l}\text { Six studies with quality overall low quality, with limitations: } \\
\text { variable consistency in significance levels but overall } \\
\text { magnitude of effect seen was improvement in spite of low } \\
\text { statistical power of studies: GRADE of evidence increased } \\
(+2)\end{array}$ \\
\hline Depression & $6[1,23,24,26-28]$ & $\begin{array}{l}N=371 \\
211(\text { ESAS }) \\
124(\text { HADS }) \\
36 \text { (SCNS-LF59) }\end{array}$ & Moderate (B) & $\begin{array}{l}\text { Overall low-quality studies with limitations but GRADE of } \\
\text { evidence increased }(+2) \text { due to studies all showing } \\
\text { consistent significant improvements in } \\
\text { depression/psychological subscales. }\end{array}$ \\
\hline Nutrition/weight & $5[24,26,28]$ & $\begin{array}{l}N=285 \\
107 \text { (PG-SGA) } \\
178 \text { (weight) }\end{array}$ & Very low (D) & $\begin{array}{l}\text { Five studies of overall low quality with serious limitations and } \\
\text { indirectness (variable interventions). Two low-quality/very } \\
\text { low-quality studies showed improved PG-SGA scores but } \\
\text { the highest quality RCT showed only significant increases in } \\
\text { protein intake. Evidence not strong enough to be upgraded. }\end{array}$ \\
\hline
\end{tabular}

*Total participants include numbers actually analysed within studies for each outcome as opposed to Table 1 showing ' $N$ ' as numbers enrolled into each trial

training classes over 3 months, and all patients managed at least half of the ONS after each training session in one RCT [22]. Similarly, for a 10-12-week CNRP, patients attended $82 \%$ of prescribed exercise sessions [26]. No adverse effects were reported, but this was only mentioned in one study [22]. In the same trial, 3-month dropout rates due to death or withdrawal were lower in the intervention group compared to the control group: $4 \%$ vs. $24 \%$, indicating feasibility. Over $90 \%$ of patients reported the CNRP as important to them; however, introducing this programme in a busy cancer centre was labour-intensive, requiring a nurse, administrative and financial support to be viable [25].

\section{Dropout rates and predictors of programme completion}

Completion rates from CNRP/PRP programmes ranged from 42 to $70 \%[24,26]$. Dropout rates due to disease progression/ death accounted for between 49 and $61 \%$ [27, 28]. Other reasons included geographical inaccessibility (39\%) [24] or unknown/personal reasons (37\%) [28]. Schedules of medical appointments made it hard to adhere to the CNRP, and at times, the amount of information to take in could be overwhelming [25]. Predictors of programme completion included lower baseline CRP levels [24, 26], lower ECOG performance

Table 3 GRADE Definifions

\begin{tabular}{|c|c|}
\hline GRADE & Definition (from [20]) \\
\hline $\operatorname{High}(\mathrm{A})$ & We are very confident that the true effect lies close to that of the estimate of the effect. \\
\hline Moderate (B) & $\begin{array}{l}\text { We are moderately confident in the effect estimate: the true effect is likely to be close to the estimate of the } \\
\text { effect, but there is a possibility that it is substantially different }\end{array}$ \\
\hline Low $(\mathrm{C})$ & Our confidence in the effect estimate is limited: the true effect may be substantially different from the estimate of the effect. \\
\hline Very low (D) & We have very little confidence in the effect estimate: the true effect is likely to be substantially different from the estimate of effect \\
\hline
\end{tabular}


status and better nutritional status [26]. Glare et al. [25] cited a baseline 6-min walk test $(6 \mathrm{MWT})>420 \mathrm{~m}$, (i.e. better endurance) as a predictor of programme completion. Although within this study programme completers demonstrated improvements in multiple domains, high dropout rates $(>50 \%)$ meant that earlier identification of the population who would best respond was recommended.

\section{Physical endurance, strength and overall function}

Studies used multiple outcome measures; however, the 6MWT was frequently cited as a marker of endurance and mean distances improved in six studies $(n=342)$. Two studies reported performance status (ECOG/KPS) as primary endpoints $(n=81)$.

Feldstain and Chasen $[27,28]$ reported significant increases in mean 6MWT distance $(t(79)=-3.91, P=<0.001$ [27] and $d=0.80$, i.e. moderate-to-large effect size, $P<0.001$ [28]) after the PRP. Studies utilising the CNRP quoted improvements in mean 6MWT distances between $41 \mathrm{~m}(95 \%$ CI 29-52 m: effect size $0.7, P$ not reported [26]) and $58 \mathrm{~m}$ [24] (non-significant, median 6MWT increase: $P=0.01$ ). Glare and Uster $[22,25]$ reported non-significant increases in 6MWT ( $n=25$, median $441 \mathrm{~m}(186-675)$ to $570 \mathrm{~m}$ (range not reported) [25], data presented graphically [22]) and other physical parameters, though both studies were underpowered. Chasen [28] reported an improvement in ECOG PS $(P<$ $0.001, t=6.43, d=0.90)$ from mean $1.8( \pm 0.7)$ to $1.29( \pm$ 0.46 ) for patients completing the PRP, and Glare [25] reported non-significant improvements in median KPS score $(n=25)$ from $70 \%$ (score $\geq 50 \%: 100 \%$ ) to $80 \%$ (score $\geq 50 \%: 100 \%$ ) in programme completers.

\section{Fatigue, weakness and insomnia}

Four studies described changes in fatigue $(n=211)$ using the Brief Fatigue Inventory (BFI) [24], the Multidimensional Fatigue Inventory (MDFI) [26, 28] and the European Organisation for Research and Treatment of Cancer (EORTC QLQ-C30) symptom scales [22].

Chasen [24] described improvements in BFI usual fatigue (5.0 (1-10)-3.0 (1-9); $P=0.03)$ and fatigue now (5.0 (0-10)3.0 (0-10); $P=0.05$ ). Furthermore, in 2013, using the MDFI, reductions in general and physical fatigue $(d=0.61$ and 0.55 , both $P<0.001)$ were reported [28]. Gagnon reported strong improvements in MDFI activity and physical fatigue (mean 4.6 [95\% CI 3.6-5.6] to 3.7 [95\% CI 2.6-4.7] respectively, both $P<$ 0.001 , effect size $0.8-1.1$ ), moderate reductions in general fatigue (mean change 2.8 [95\% CI 1.8-3.8], $P<0.0001$, effect size 0.7 ) and small but significant improvements in motivation and mental fatigue (mean change 1.6 [95\% CI 0.8-2.5], $P=0.0004$ and 1.7 [95\% CI 0.8-2.6] $P=0.0005$ : effect size both 0.4 ). Reductions were seen in weakness (mean change 1.5 [95\% CI 1.1-1.8], $P<0.0001$, effect size 0.7 ) as well as reductions in sleepiness and insomnia (mean change 1.1 [95\% CI 0.6-1.6], $P<0.0001$ and mean change 1.0 [95\% CI 0.5-1.4], $P=0.0001$ effect size both 0.4) [26].

\section{Effects on depression and quality of life}

Six studies included endpoints examining depression $(n=371)$ using the Edmonton Symptom Assessment Scale (ESAS) [24, 26, 28], the Hospital Anxiety and Depression Scale (HADs) [1, 27] and the psychological subscale of the Supportive Care Needs Survey Long Form (SCNS-LF59) [23]. Studies frequently mentioned QoL but only three studies reported a QoL outcome using questions from the ESAS [26], EORTC QLQC30 [22] and EQ-5D/EQ-VAS questionnaires [23].

Chasen reported improvements in (ESAS) nervousness and depression (4.5 (0-10)-1.5 (0-5); $P=0.02$ and (3.0 (0-9)-2.0 $(0-7) ; P=0.04$ respectively) in 2010 [24] and depression scores for those completing the PRP in $2013(P=0.005$, $d=0.37$ ) [28]. Similarly, Gagnon [26] reported reductions in (ESAS) depression scores (mean change 1.4 (95\% CI 1.1-1.8) $P<0.0001$, effect size 0.7 ) as well as reduced (DT) distress (mean change 1.4 (95\% CI 0.9-1.9) $P<0.0001$, effect size 0.5 ), improved (CT) coping (mean change 1.8 (95\% CI 1.22.4) $P<0.0001$, effect size 0.7 ) and (ESAS) QoL (mean change $1.0(95 \%$ CI $0.6-1.3) P<0.0001$ effect size 0.5$)$ after the CNRP. One RCT demonstrated reduced unmet psychological support needs on the psychological subscale of the SCNS compared with controls (adjusted difference -16.8 points (95\% CI -28.34 to -5.3$) P=0.006)$ and improvements in (EQ-5D) self-reported health state (12.8, (95\% CI 3.2-22.4) $P=0.01)$ [23]. Conversely, the other RCT [22] showed no difference global QoL. There was a non-significant trend toward improvement; however, this trial was curtailed due to poor recruitment and lacked power. Feldstain [27] described increased self-efficacy $(27.86(\mathrm{SD}=6.16)$ to 31.23 units $(\mathrm{SD}=$ 5.77), $P<0.001)$ and reduced depression scores $(7.14(\mathrm{SD}=$ $3.91)$ to 5.95 units $(\mathrm{SD}=3.51), P=0.002)$ after the PRP. Changes in 'self-efficacy' (the perception that one can influence life events/quality of functioning) accounted for the greatest change $(11 \%)$ in depression scores. In a subsequent study [1], depression score improvements were maintained 3 months post-PRP (mean difference T1-T3 = 2.21, SE 0.78, $P=0.007$ ).

\section{Nutritional status}

Two studies measured weight as an outcome [22, 26], two used the Patient-Generated Subjective Global Assessment (PG-SGA) [24, 28] and one used a combination of both [25]. Comparison between studies is hampered by lack of detail on nutritional interventions, heterogeneity of subjects and varied outcome measures. Nutritional counselling, dietary advice and oral nutritional supplements (ONS) are mentioned by most. Details of dietary interventions varied: $72 \%$ saw the 
physician, physiotherapist and dietitian, with $25 \%$ seeing the physician and dietitian only in one [25]; 60-70\% saw the dietitian in another [1]; and in another, $94.7 \%$ received dietary counselling, with $80.2 \%$ receiving ONS [26]. One RCT ensured patients received $\geq 1.2 \mathrm{~g}$ protein $/ \mathrm{kg} /$ day and encouraged protein dense ONS (18-20 g in 125-200 mL) after exercise. Significant improvements in protein intake $(P=0.01)$, but no significant differences in energy intake or nutritional status were seen between arms: indeed, weight increased in both [22]. Patients undergoing nutritional interventions within multidisciplinary programmes maintained (77\% within $2 \mathrm{~kg}$ ) [26] or increased their weight [22], although longitudinal data is lacking. Increases in protein intake were not maintained 3 months post-intervention, dropping below baseline in both groups, more so in the control group [22].

PG-SGA score improvements (median baseline 12.0 (2-24), to $9.0(1-18)$ at completion $P=0.05)$ were reported following the CNRP [24] and also post-PRP (baseline mean $( \pm \mathrm{SD}) 8.15$ ( \pm 5.29$)$ to 5.98 ( \pm 4.14$), t=3.49, P=0.001, d=0.46$ ) [28]. There was a higher mean PG-SGA score $(89 \% \geq 9$ versus $70 \%$ $\geq 9$ ) in dropouts of than those who returned for their 2-month CNRP follow-up [25].

\section{Cost-effectiveness}

One RCT $(n=41)$ examined the cost-effectiveness of a 3month, complex hospice-based rehabilitation programme plus usual care versus usual care alone [23]. The intervention was associated with greater total costs (mean difference $£ 955,95 \%$ CI £82-£1975) and greater QoL (mean difference 0.05 QALYs, 95\% CI 0.000-0.112) resulting in an incremental cost-effectiveness ratio (ICER) of $£ 19,391$ per qualityadjusted life year (QALY) gained. The cost per QALY was only calculated over the 3-month (intervention) period and was close to the $£ 20,000$ threshold often used for incorporation of an intervention into the UK National Health Service. The authors postulated that if the benefits of the programme were maintained for 1 year, the ICER would decrease to approximately $£ 4400$ making the projection cost-effective in $92.7 \%$ of simulations at a threshold of $£ 20,000$ per QALY.

\section{Discussion}

There are few data available for multi-modal rehabilitation programmes incorporating exercise and nutritional interventions for patients with incurable cancer. However, of those outcomes important to patients, many showed improvements following the interventions described. Factors associated with programme completion are higher baseline nutritional or functional status and lower levels of inflammation. Of the studies analysed, methodological quality was frequently limited by study design and statistical power. Heterogeneity of study design (including interventions and outcome measures) meant meta-analysis was not appropriate.

In patients with incurable cancer, the highest quality of evidence pertains to improvements in depression and physical endurance following multi-modal rehabilitation programmes including exercise and nutritional support. Depression is one of the commonest mental health problems in patients with advanced cancer [29]. Six studies showed improvements in depression scores, using outcomes including the Hospital Anxiety and Depression Scale (HADs). This scale, however, does not differentiate clinical depression from sub-threshold symptomatology, which is a limitation to its use in this patient population [27].

A high level of evidence exists for exercise in rehabilitation trials $[2,30]$, and this review suggests that the combination of exercise and nutritional support also improves physical endurance in patients with incurable cancer. Evidence for change in overall function remains very low due to serious limitations in the evidence (Table 2). Plausibly however, improvements in physical endurance may impact on overall function via reductions in dependency.

Evidence for improved fatigue remains low. This finding is in keeping with the lack of interventions for fatigue in advanced incurable disease. Rehabilitation studies in patients with cancer are at risk of selection bias as patients recruited may be more motivated, acknowledged by Uster [22]. Three studies measured QoL, but overall evidence for improvement remained low. Cancer negatively affects QoL by many modalities; hence, the necessity of a multi-modal approach in this patient group. Results for nutritional parameters were variable, and it was difficult to make comparisons, resulting in a very low rating of evidence. Weight is a key feature of cachexia and (as an outcome) is meaningful to both patients and clinicians [31], but does not take into account body composition. PG-SGA scores reflect changes in weight but also symptoms so may not reflect alterations in nutritional status alone. Furthermore, patients with incurable cancer are more likely to be at a 'refractory' stage of cachexia that is poorly responsive to treatment; therefore, this level of evidence is unsurprising [9]. A further confounding factor is that of contamination, whereby the control group mimics the intervention. Both groups gained weight and improved hand grip strength within Uster's RCT, which may have contributed to a lack of statistical significance [22].

Cancer rehabilitation trials are frequently limited by design and sample size and high attrition rates are common [32]. Recruitment issues were encountered in both RCTs; one cut short due to poor recruitment [22], the other recruiting just $17 \%$ of expected patients. In this RCT, 189 eligible patients were not approached, and interviews with recruiting clinicians revealed reasons including discomfort with the trial design, lack of confidence discussing prognosis and anxieties about delivering the intervention at a hospice [23]. Other barriers to recruitment include difficulties identifying participants 
(complex inclusion criteria) and high refusal rates (competing priorities, fear of randomisation to non-preferred arm, lack of acceptable control). Healthcare professional gatekeeping is one of the most significant barriers to recruitment [33]; however, patients find symptom control trials beneficial irrespective of whether they obtain improvements in their symptoms [34].

Some of the findings presented herein are worthy of comparison to other diseases. The importance of exercise and nutritional intervention is acknowledged in models of rehabilitation for non-malignant disease, where cachexia may be present. Pulmonary rehabilitation (PR) has included exercise as a cornerstone for many years. Research on muscle dysfunction in patients with chronic obstructive pulmonary disease (COPD) has shown that multi-modal interventions including exercise and nutritional supplementation can have beneficial effects on body weight, exercise tolerance, physical activity, depression and survival $[35,36]$. There is now a shift toward earlier PR to improve exercise tolerance and physical activity and to promote self-efficacy and behavioural change while reducing exacerbations [36]. These observations provide further grounds for optimism that exercise and nutrition-based rehabilitation programmes in patients with incurable cancer are viable.

It is clear from work to date that the principles employed in the treatment of cancer cachexia may be useful in rehabilitation. Work is ongoing to define the best approach to target cachexia at all stages of disease: including 'prehabilitation' for patients undergoing cancer surgery [37], and a phase 3 trial is underway of a multi-modal cachexia treatment (exercise, nutrition plus anti-inflammatories) for patients undergoing chemotherapy [31]. A feasibility trial of a multimodal rehabilitation programme combining exercise and nutritional support for hospice outpatients with incurable cancer is also in progress [38]. There is a growing body of evidence for the use of new technologies in oncology trials such as physical activity monitors, which provide an objective measurement of patient activity in their usual environment [39]. There is now strong international consensus that cachexia is a multi-modal problem which requires multi-modal treatment $[10,11]$. One of the challenges in cancer cachexia, however, is that the optimal endpoints are not clear, and this appears similar in cancer rehabilitation studies where consensus on endpoints is not evident [40]. Potential outcomes are numerous, though it is important that measures are validated and clinically meaningful [30]. GRADE discourages the use of 'surrogate outcomes', which can result in downgrading of evidence for indirectness [20]. The aforementioned difficulties in comparing trials due to the clinical and methodological heterogeneity of interventions and outcomes may be one reason for the slow growth of evidence in this field. There are inherent difficulties however, performing clinical trials in a field where personalised care makes standardising interventions challenging [30].
For patients with incurable cancer, concerns about nutrition, loss of function and increased dependency are commonplace. Loss of independence can compromise a person's sense of dignity and fears of functional decline can surpass fears of impending death [41]. As the population changes, with improvements in anti-cancer treatment and greater numbers of patients treated under the umbrella of palliative care, there is the need to enable patients to live their lives as fully as possible, while minimising social-care costs. This approach, incorporating rehabilitation, places living before dying and is at the heart of palliative care [6].

\section{Limitations}

The search strategy may have precluded relevant articles due to stringency of the search criteria. One such factor was exclusion of studies reporting results for 'cancer survivors'. The definition of this term is very broad, encompassing patients from initial diagnosis to death, and may also include family, friends or caregivers [42]. Application of the GRADE criteria can be advantageous due to transparency of judgements about quality; however, limitations of the system (including its use for assessment of individual studies) are acknowledged [43]. A further challenge with GRADE is the complexity which can result in poor-to moderate inter-rater agreement [44]. Our GRADE checklist was designed to improve this and, though effective, it is not a validated tool. The lack of randomised control trials (two studies) meant that meta-analysis was not possible. However, the use of the robustly validated GRADE system of analysis [19-21] ensured that conclusions drawn were as accurate as possible.

\section{Conclusion}

This review demonstrates that in spite of limited data, multimodal rehabilitation programmes incorporating exercise and nutritional interventions improve many outcomes that are important to patients with incurable cancer, most notably those relating to physical endurance and depression. This finding, along with factors associated with programme completion, lends further support to the argument that exercise and nutritional intervention should form integral components of cancer rehabilitation. Multi-modal treatments are evolving for cancer cachexia, and these may be usefully adapted to cancer rehabilitation.

There are multiple opportunities to improve patient wellbeing throughout all phases of cancer care: from the point of diagnosis, prior to treatment and at the advanced stages of incurable disease [4, 8]. Modern palliative care should now encompass rehabilitation [6] as well as forming an integral and concurrent element of active cancer care [45]. Rehabilitation for patients with incurable cancer has the potential to significantly improve functional status and QoL for the ever-increasing numbers of patients 'living with cancer', 
with potentially large socio-economic benefits. Further, carefully designed high-quality trials are needed, but the current shift toward a joint rehabilitative-palliative approach throughout the cancer trajectory shines a light in the dark for cancer patients of the future.

Acknowledgements Thanks to St Columba's Hospice and the University of Edinburgh for supporting this work as part of Dr. Hall's position as Medical Research Fellow.

Funding This work was funded by St Columba's Hospice as part of Dr Hall's MD as Medical Research Fellow.

\section{Compliance with ethical standards}

The authors have control of the data contained within this review and this may be reviewed by the journal on request.

Conflict of interest The authors declare that they have no conflict of interest.

\section{Appendix. Search Strategy}

All terms searched within 'Title'. Limits: Human subjects, English language, year 1990-current.

MEDLINE. Total 781

1. Rehabilitation + Cancer: $(578)$

2. Rehabilitation + Cancer + Exercise: (36)

3. Rehabilitation + Cancer + Nutrition: (3)

4. Rehabilitation + Cancer + Exercise + Nutrition: $(0)$

5. Exercise + Cancer + Nutrition: $(21)$

6. Palliative + Rehabilitation: (42)

7. Palliative + Exercise + Nutrition: $(0)$

8. Prehabilitation: $(81)$

9. Prehabilitation + Cancer: (18)

10. Prehabilitation + Cancer + Palliative: $(0)$

11. Prehabilitation + Palliative: $(0)$

12. Prehabilitation + Nutrition $(2)$

\section{EMBASE. Total 1625}

1. Rehabilitation + Cancer: (1168)

2. Rehabilitation + Cancer + Exercise: $(65)$

3. Rehabilitation + Cancer + Nutrition: $(10)$

4. Rehabilitation + Cancer + Exercise + Nutrition: $(0)$

5. Exercise + Cancer + Nutrition: $(50)$

6. Palliative + Rehabilitation: (96)

7. Palliative + Exercise + Nutrition: (3)

8. Prehabilitation: (180)

9. Prehabilitation + Cancer: $(50)$

10. Prehabilitation + Cancer + Palliative: $(0)$

11. Prehabilitation + Palliative: $(0)$
12. Prehabilitation + Nutrition (3) Cochrane Library. Total 18

1. Rehabilitation + Cancer: (2)

2. Rehabilitation + Cancer + Exercise: (4)

3. Rehabilitation + Cancer + Nutrition: $(0)$

4. Rehabilitation + Cancer + Exercise + Nutrition: $(0)$

5. Exercise + Cancer + Nutrition: (1)

6. Palliative + Rehabilitation: (2)

7. Palliative + exercise + nutrition: $(0)$

8. Prehabilitation: (1)

9. Prehabilitation + Cancer: $(8)$

10. Prehabilitation + Cancer + Palliative: $(0)$

11. Prehabilitation + Palliative: $(0)$

12. Prehabilitation + nutrition: $(0)$

Open Access This article is distributed under the terms of the Creative Commons Attribution 4.0 International License (http:// creativecommons.org/licenses/by/4.0/), which permits unrestricted use, distribution, and reproduction in any medium, provided you give appropriate credit to the original author(s) and the source, provide a link to the Creative Commons license, and indicate if changes were made.

\section{References}

1. Feldstain A, Lebel S, Chasen MR (2017) The longitudinal course of depression symptomatology following a palliative rehabilitation program. Qual Life Res 26(7):1809-1818. https://doi.org/10. 1007/s11136-017-1531-7

2. Salakari MR, Surakka T, Nurminen R et al (2015) Effects of rehabilitation among patients with advances cancer: a systematic review. Acta Oncol 54(5):618-628. https://doi.org/10.3109/ 0284186X.2014.996661

3. Mariotto AB, Yabroff KR, Shao Y et al (2011) Projections of the cost of cancer care in the United States: 2010-2020. J Natl Cancer Inst 103(2):117-128. https://doi.org/10.1093/jnci/djq495

4. Silver JK, Baima J, Mayer RS (2013) Impairment-driven cancer rehabilitation: an essential component of quality care and survivorship. CA Cancer J Clin 63(5):295-317. https://doi.org/10.3322/ caac. 21186

5. Chasen M, Bhargava R, MacDonald N (2014) Rehabilitation for patients with advanced cancer. CMAJ 186(14):1071-1075. https:// doi.org/10.1503/cmaj.131402

6. Tiberini RRH Rehabilitative palliative care enabling people to live fully until they die: a challenge for the 21st century. Hospice UK, St Joseph's Hospice, St Christopher's, Burdett Trust for Nursing, United Kingdom

7. Maddocks M, Payne S (2017) Rehabilation: additional palliative care approaches, 3rd edn. Oxford University Press

8. Silver JK, Raj VS, Fu JB, Wisotzky EM, Smith SR, Kirch RA (2015) Cancer rehabilitation and palliative care: critical components in the delivery of high-quality oncology services. Support Care Cancer 23(12):3633-3643. https://doi.org/10.1007/s00520015-2916-1

9. Fearon K, Strasser F, Anker SD, Bosaeus I, Bruera E, Fainsinger RL, Jatoi A, Loprinzi C, MacDonald N, Mantovani G, Davis M, Muscaritoli M, Ottery F, Radbruch L, Ravasco P, Walsh D, Wilcock A, Kaasa S, Baracos VE (2011) Definition and classification of 
cancer cachexia: an international consensus. Lancet Oncol 12(5): 489-495. https://doi.org/10.1016/S1470-2045(10)70218-7

10. Baracos VE, Martin L, Korc M, Guttridge DC, Fearon KCH (2018) Cancer-associated cachexia. Nat Rev Dis Primers 4:17105. https:// doi.org/10.1038/nrdp.2017.105

11. Fearon KC (2008) Cancer cachexia: developing multimodal therapy for a multidimensional problem. Eur J Cancer 44(8):1124-1132. https://doi.org/10.1016/j.ejca.2008.02.033

12. Dewys WD, Begg C, Lavin PT, Band PR, Bennett JM, Bertino JR, Cohen MH, Douglass HO Jr, Engstrom PF, Ezdinli EZ, Horton J, Johnson GJ, Moertel CG, Oken MM, Perlia C, Rosenbaum C, Silverstein MN, Skeel RT, Sponzo RW, Tormey DC (1980) Prognostic effect of weight loss prior to chemotherapy in cancer patients. Eastern Cooperative Oncology Group. Am J Med 69(4): 491-497

13. Stephens NA, Skipworth RJ, Fearon KC (2008) Cachexia, survival and the acute phase response. Curr Opin Support Palliat Care 2(4): 267-274. https://doi.org/10.1097/SPC.0b013e3283186be2

14. Gullett NP, Mazurak VC, Hebbar G, Ziegler TR (2011) Nutritional interventions for cancer-induced cachexia. Curr Probl Cancer 35(2):58-90. https://doi.org/10.1016/j.currproblcancer.2011.01. 001

15. Solheim TS, Laird BJ, Balstad T et al (2017) A randomized phase II feasibility trial of a multimodal intervention for the management of cachexia in lung and pancreatic cancer. J Cachexia Sarcopenia Muscle In Press

16. Jimenez A, Madero R, Alonso A et al (2011) Symptom clusters in advanced cancer. J Pain Symptom Manag 42(1):24-31. https://doi. org/10.1016/j.jpainsymman.2010.10.266

17. Aktas A, Walsh D, Rybicki L (2010) Symptom clusters: myth or reality? Palliat Med 24(4):373-385. https://doi.org/10.1177/ 0269216310367842

18. Litterini AJ, Fieler VK, Cavanaugh JT, Lee JQ (2013) Differential effects of cardiovascular and resistance exercise on functional mobility in individuals with advanced cancer: a randomized trial. Arch Phys Med Rehabil 94(12):2329-2335. https://doi.org/10.1016/j. apmr.2013.06.008

19. Meader N, King K, Llewellyn A, Norman G, Brown J, Rodgers M, Moe-Byrne T, Higgins JPT, Sowden A, Stewart G (2014) A checklist designed to aid consistency and reproducibility of GRADE assessments: development and pilot validation. Syst Rev 3:82. https://doi.org/10.1186/2046-4053-3-82

20. Schünemann HBJ, Guyatt G. Oxman A. GRADE Handbook. 2013. http://gdt.guidelinedevelopment.org/app/handbook/handbook.html (accessed 25-5-18)

21. Atkins D, Eccles M, Flottorp S et al (2004) Systems for grading the quality of evidence and the strength of recommendations I: critical appraisal of existing approaches the GRADE Working Group. BMC Health Serv Res 4(1):38. https://doi.org/10.1186/14726963-4-38

22. Uster A, Ruehlin M, Mey S, Gisi D, Knols R, Imoberdorf R, Pless M, Ballmer PE (2017) Effects of nutrition and physical exercise intervention in palliative cancer patients: a randomized controlled trial. Clin Nutr 37:1202-1209. https://doi.org/10.1016/j.clnu.2017. 05.027

23. Jones L, Fitzgerald G, Leurent B et al (2013) Rehabilitation in advanced, progressive, recurrent cancer: a randomized controlled trial. J Pain Symptom Manag 46(3):315-25 e3. https://doi.org/10. 1016/j.jpainsymman.2012.08.017

24. Chasen MR, Bhargava R (2010) A rehabilitation program for patients with gastroesophageal cancer-a pilot study. Support Care Cancer 18(Suppl 2):S35-S40. https://doi.org/10.1007/s00520010-0828-7

25. Glare P, Jongs W, Zafiropoulos B (2011) Establishing a cancer nutrition rehabilitation program (CNRP) for ambulatory patients attending an Australian cancer center. Support Care Cancer 19(4): 445-454. https://doi.org/10.1007/s00520-010-0834-9

26. Gagnon B, Murphy J, Eades M, Lemoignan J, Jelowicki M, Carney S, Amdouni S, di Dio P, Chasen M, MacDonald N (2013) A prospective evaluation of an interdisciplinary nutrition-rehabilitation program for patients with advanced cancer. Curr Oncol 20(6): 310-318. https://doi.org/10.3747/co.20.1612

27. Feldstain A, Lebel S, Chasen MR (2016) An interdisciplinary palliative rehabilitation intervention bolstering general self-efficacy to attenuate symptoms of depression in patients living with advanced cancer. Support Care Cancer 24(1):109-117. https://doi.org/10. 1007/s00520-015-2751-4

28. Chasen MR, Feldstain A, Gravelle D, MacDonald N, Pereira J (2013) An interprofessional palliative care oncology rehabilitation program: effects on function and predictors of program completion. Curr Oncol 20(6):301-309. https://doi.org/10.3747/co.20.1607

29. Al-Shahri MZ, Eldali AM, Al-Zahrani O (2012) Prevalence and severity of suffering among patients with advanced cancer. Support Care Cancer 20(12):3137-3140. https://doi.org/10.1007/ s00520-012-1443-6

30. Gerber LH, Hodsdon B, Comis LE et al (2017) A brief historical perspective of cancer rehabilitation and contributions from the National Institutes of Health. PM R 9(9S2):S297-S304. https:// doi.org/10.1016/j.pmrj.2017.07.005

31. Solheim TS, Laird BJA Balstad TR, Bye A, Stene G, Baracos V, Strasser F, Griffiths G, Maddocks M, Fallon M, Kaasa S, Fearon K (2018) Cancer cachexia: rationale for the MENAC (multimodalexercise, nutrition and anti- inflammatory medication for Cachexia) trial. BMJ Support Palliat Care 0:1-8. https://doi.org/ 10.1136/bmjspcare-2017-001440

32. Hui D, Glitza I, Chisholm G, Yennu S, Bruera E (2013) Attrition rates, reasons, and predictive factors in supportive care and palliative oncology clinical trials. Cancer 119(5):1098-1105. https://doi. org/10.1002/cncr.27854

33. Dunleavy L, Walshe C, Oriani A, Preston N (2018) Using the 'Social Marketing Mix Framework' to explore recruitment barriers and facilitators in palliative care randomised controlled trials? A narrative synthesis review. Palliat Med 32(5):990-1009. https:// doi.org/10.1177/0269216318757623

34. Middlemiss T, Lloyd-Williams M, Laird BJ, Fallon MT (2015) Symptom control trials in patients with advanced cancer: a qualitative study. J Pain Symptom Manag 50(5):642-649 e1. https://doi. org/10.1016/j.jpainsymman.2015.05.009

35. van de Bool C, Rutten EPA, van Helvoort A, Franssen FME, Wouters EFM, Schols AMWJ (2017) A randomized clinical trial investigating the efficacy of targeted nutrition as adjunct to exercise training in COPD. J Cachexia Sarcopenia Muscle 8(5):748-758. https://doi.org/10.1002/jcsm.12219

36. Spruit MA, Singh SJ, Garvey C, ZuWallack R, Nici L, Rochester C, Hill K, Holland AE, Lareau SC, Man WD, Pitta F, Sewell L, Raskin J, Bourbeau J, Crouch R, Franssen FM, Casaburi R, Vercoulen JH, Vogiatzis I, Gosselink R, Clini EM, Effing TW, Maltais F, van der Palen J, Troosters T, Janssen DJ, Collins E, Garcia-Aymerich J, Brooks D, Fahy BF, Puhan MA, Hoogendoorn M, Garrod R, Schols AM, Carlin B, Benzo R, Meek P, Morgan M, Rutten-van Mölken M, Ries AL, Make B, Goldstein RS, Dowson CA, Brozek JL, Donner CF, Wouters EF, ATS/ERS Task Force on Pulmonary Rehabilitation (2013) An official American Thoracic Society/ European Respiratory Society statement: key concepts and advances in pulmonary rehabilitation. Am J Respir Crit Care Med 188(8):e13-e64. https://doi.org/10.1164/rccm.201309-1634ST

37. Chen BP, Awasthi R, Sweet SN, Minnella EM, Bergdahl A, Santa Mina D, Carli F, Scheede-Bergdahl C (2017) Four-week prehabilitation program is sufficient to modify exercise behaviors and improve preoperative functional walking capacity in patients 
with colorectal cancer. Support Care Cancer 25(1):33-40. https:// doi.org/10.1007/s00520-016-3379-8

38. Hall CC, Norris L, Dixon L, Cook J, Maddocks M, Graham C, Tuck S, Haraldsdottir E, Brown D, Lloyd A, Finucane A, Hall P, Diernberger K, Skipworth RJE, Fallon M, Laird BJ (2018) A randomised, phase II, unblinded trial of an Exercise and Nutrition-based Rehabilitation programme (ENeRgy) versus standard care in patients with cancer: feasibility trial protocol. Pilot Feasibility Stud 4:192. https://doi.org/10.1186/s40814-018-0381-6

39. Maddocks M, Granger CL (2018) Measurement of physical activity in clinical practice and research: advances in cancer and chronic respiratory disease. Curr Opin Support Palliat Care 12(3):219 226. https://doi.org/10.1097/SPC.0000000000000372

40. Laird BJB, Balstad TR, Solheim TS (2018) Endpoints in cachexia trials: where to start. Current opinion in supportive and palliative care [In Press]

41. Baile WF, Palmer JL, Bruera E et al (2011) Assessment of palliative care cancer patients' most important concerns. Support Care Cancer 19(4):475-481. https://doi.org/10.1007/s00520-010-0839-4 [published Online First: 2010/04/20]

42. Institute NC. About cancer survivorship research: survivorship definitions 2006 [updated November 6], 2006. Available from: https:// web.archive.org/web/20110102141955/http://cancercontrol.cancer. gov/ocs/definitions.html2018
43. Guyatt GH, Oxman AD, Vist G, Kunz R, Brozek J, Alonso-Coello P, Montori V, Akl EA, Djulbegovic B, Falck-Ytter Y, Norris SL, Williams JW Jr, Atkins D, Meerpohl J, Schünemann HJ (2011) GRADE guidelines: 4. Rating the quality of evidence-study limitations (risk of bias). J Clin Epidemiol 64(4):407-415. https://doi. org/10.1016/j.jclinepi.2010.07.017

44. Hartling L, Fernandes RM, Seida J, Vandermeer B, Dryden DM (2012) From the trenches: a cross-sectional study applying the GRADE tool in systematic reviews of healthcare interventions. PLoS One 7(4):e34697. https://doi.org/10.1371/journal.pone. 0034697

45. Ferrell BR, Temel JS, Temin S, Alesi ER, Balboni TA, Basch EM, Firn JI, Paice JA, Peppercorn JM, Phillips T, Stovall EL, Zimmermann C, Smith TJ (2017) Integration of palliative care into standard oncology care: American Society of Clinical Oncology clinical practice guideline update. J Clin Oncol 35(1):96-112. https://doi.org/10.1200/JCO.2016.70.1474

Publisher's note Springer Nature remains neutral with regard to jurisdictional claims in published maps and institutional affiliations. 